\title{
LHX2 Is Necessary for the Maintenance of Optic Identity and for the Progression of Optic Morphogenesis
}

\author{
Achira Roy, ${ }^{1}$ Jimmy de Melo, ${ }^{2}$ Dhananjay Chaturvedi, ${ }^{1}$ Thuzar Thein, ${ }^{2}$ Alfredo Cabrera-Socorro, ${ }^{1,7}$ Corinne Houart ${ }^{8}$ \\ Gundela Meyer, ${ }^{7}$ Seth Blackshaw, ${ }^{2,3,4,5,6}$ and Shubha Tole ${ }^{1}$ \\ ${ }^{1}$ Tata Institute of Fundamental Research, Mumbai, India 400005, 2 Solomon H. Snyder Department of Neuroscience, ${ }^{3}$ Department of Neurology, \\ ${ }^{4}$ Department of Ophthalmology, ${ }^{5}$ Center for High-Throughput Biology, and ${ }^{6}$ Institute for Cell Engineering, Johns Hopkins University School of Medicine, \\ Baltimore, Maryland 21287, ${ }^{7}$ University of La Laguna, Tenerife, Spain 38071, and ${ }^{8}$ King's College, London, United Kingdom SE1 1UL
}

Eye formation is regulated by a complex network of eye field transcription factors (EFTFs), including LIM-homeodomain gene LHX2. We disrupted LHX2 function at different stages during this process using a conditional knock-out strategy in mice. We find that LHX2 function is required in an ongoing fashion to maintain optic identity across multiple stages, from the formation of the optic vesicle to the differentiation of the neuroretina. At each stage, loss of $L h \times 2$ led to upregulation of a set of molecular markers that are normally expressed in the thalamic eminence and in the anterodorsal hypothalamus in a portion of the optic vesicle or retina. Furthermore, the longer LHX2 function was maintained, the further optic morphogenesis progressed. Early loss of function caused profound mispatterning of the entire telencephalic-optic-hypothalamic field, such that the optic vesicle became mispositioned and appeared to arise from the diencephalictelencephalic boundary. At subsequent stages, loss of $L h \times 2$ did not affect optic vesicle position but caused arrest of optic cup formation. If $L h x 2$ was selectively disrupted in the neuroretina from E11.5, the neuroretina showed gross dysmorphology along with aberrant expression of markers specific to the thalamic eminence and anterodorsal hypothalamus. Our findings indicate a continual requirement for LHX2 throughout the early stages of optic development, not only to maintain optic identity by suppressing alternative fates but also to mediate multiple steps of optic morphogenesis. These findings provide new insight into the anophthalmic phenotype of the $L h x 2$ mutant and reveal novel roles for this transcription factor in eye development.

\section{Introduction}

The vertebrate eye is an elegant structure arising from the neuroepithelium of the anterior neural plate as a result of a series of highly coordinated patterning events. The process starts with the specification of the eye field, demarcating a territory between what would form the telencephalic and hypothalamic neuroepithelium (Inoue et al., 2000; Wilson and Houart, 2004; Esteve and Bovolenta, 2006), involving regulatory molecules that are referred to as the eye field transcription factors (EFTFs), namely, Rax, Pax6, Lhx2, Six3, Six6, ET/Tbx3, and tll/ Nr2e1 (Chow and Lang, 2001; Wilson and Houart, 2004). Symmetrical bilateral evaginations called optic sulci arise by embryonic day 8.5 (E8.5)

\footnotetext{
Received Sept. 2, 2012; revised Feb. 28, 2013; accepted March 8, 2013.

Author contributions: A.R., G.M., S.B., and S.T. designed research; A.R., J.d.M., D.C., T.T., and A.C.-S. performed research; A.R., C.H., G.M., S.B., and S.T. analyzed data; A.R., G.M., S.B., and S.T. wrote the paper.

This work was supported by the Tata Institute of Fundamental Research intramural funding to S.T. and National Institutes of Health Grant R01EY020560 to S.B. S.B. was a W.M. Keck Distinguished Young Investigator in Medical Research. A.C.S. was supported by a traveling Fellowship from the journal Development. We thank colleagues F. D. Porter (Lhx2 null), Edwin S. Monuki (Lhx2 floxed), A. Stoykova (Pax6sey), and C. Cepko (Chx10-(re) for generous gifts of mutant and transgenic mouse breeding pairs; the TIFR Animal house staff for excellent support; Pushkar Joshi for critical comments on this manuscript; Stephen M. Jane for the DNA extraction protocol for young embryos; and A. Pierani, C. Cepko, E. Grove, R. McInnes, Y. Nakagawa, T. Okada, F. D. Porter, C. Ragsdale, J. L. R. Rubenstein, J. Sen, and $Y$. Zhao for DNA reagents.

The authors declare no competing financial interests.

Correspondence should be addressed to Dr. Shubha Tole, B-304, Department of Biological Sciences, Tata Institute of Fundamental Research, Homi Bhabha Road, Colaba, Mumbai, India 400005. E-mail: shubhatole@gmail.com.

DOI:10.1523/JNEUROSCI.4216-12.2013

Copyright $\odot 2013$ the authors $\quad 0270-6474 / 13 / 336877-08 \$ 15.00 / 0$
}

and progress to form the optic vesicles by E9.5 (Theiler, 1972). In a coordinated cascade of molecular and cellular events that follows, the optic vesicle differentiates to an optic cup with a neuroretina that is regionally patterned (Chow and Lang, 2001; Martínez-Morales et al., 2004). Disruptions in these early developmental stages lead to anomalies, including anophthalmia, micropthalmia, and retinal dysplasia (Graw, 2003; Fitzpatrick and van Heyningen, 2005)

LIM-HD gene Lhx2 is expressed from the earliest stages of optic development and is a critical EFTF. Cocktails of EFTFs without LHX2 that could produce ectopic eyes in Xenopus always induced endogenous $L h \times 2$ expression in those ectopic eye fields (Zuber et al., 2003). Absence of $L h x 2$ in mice causes anophthalmia; the optic vesicles begin to extend toward the ectoderm but arrest thereafter without forming optic cups (Porter et al., 1997). Expression of important EFTFs, namely, Rax, Pax6, and Six3, at the anterior neural plate stage was found to be reduced in the $L h \times 2$ mutant, indicating requirement of LHX2 in the earliest stage of optic development (Tetreault et al., 2009). Yun et al. (2009) highlighted a later role for LHX2, in the transition of the optic vesicle to the optic cup. Using explant culture techniques to test differentiation in control and mutant optic vesicles, Yun et al. (2009) proposed that LHX2 integrates extrinsic cues, such as BMPs with intrinsic transcription factors, serving an important role in the regulatory network for optic morphogenesis and retinal differentiation.

We examined the temporal requirement for LHX2 in optic development using a conditional knock-out strategy in mice. We 
find an ongoing role for LHX2 in the progressive morphogenesis of the developing eye, including patterning of the neuroretina. Furthermore, we find that LHX2 is required to maintain optic identity by continuously suppressing alternative fates corresponding to the thalamic eminence and anterodorsal hypothalamus. Our results reveal unexpected complexity in the role of LHX2 in regulating eye development.

\section{Materials and Methods}

Mice and sample preparation. All procedures followed Institute Animal Ethics Committee guidelines and National Institutes of Health guidelines for the care and use of animals. Timed pregnant $L h \times 2^{+/-}$mice (gift from F. D. Porter, National Institutes of Health) and Pax6 small eye $($ Pax6sey/+) mice (gift from A. Stoykova) were used. A tamoxifen-inducible CreER mouse line (strain B6;129-Gt(ROSA)26Sor ${ }^{\text {tm 1 (cre/ERT)Nat } / \text {; }}$; stock \#004847) was obtained from the The Jackson Laboratory. The floxed $\operatorname{Lh} x 2$ line $\left(\operatorname{Lh} x 2^{\text {lox/lox }}\right)$ was obtained from E.S. Monuki's laboratory. Chx10-Cre mice were a gift from C. Cepko. Pregnant dams were obtained from the Tata Institute animal breeding facility. Early age embryos were staged by somite number (ss). For in situ hybridization, the embryos were harvested in PBS, the embryos fixed in 4\% PFA, equilibrated in 30\% sucrose made in $4 \%$ PFA, and sectioned at $30 \mu \mathrm{m}$ on a freezing microtome. Fifty $L h \times 2$ mutant embryos were examined, and there was $100 \%$ penetrance in the phenotype (i.e., the presence of the mutant vesicle at the diencephalic-telencephalic boundary [DTB]).

Histochemical procedures. In situ hybridization was performed as described previously (Bulchand et al., 2003). Briefly, the hybridization was performed overnight at $70^{\circ} \mathrm{C}$ in $4 \times$ SSC, $50 \%$ formamide, and $10 \%$ SDS. Posthybridization washes were at $70^{\circ} \mathrm{C}$ in $2 \times \mathrm{SSC}$ and $50 \%$ formamide. These were followed by washes in $2 \times$ SSC, 0.2 SSC, and then Tris-buffered saline-1\% Tween 20. Anti-digoxigenin Fab fragments (Roche) were used at 1:5000 in Tris-buffered saline-1\% Tween 20, and the color reaction using NBT/BCIP (Roche) was performed according to the manufacturer's instructions.

Administration of tamoxifen. Tamoxifen (Sigma) dissolved in corn oil $(10 \mathrm{mg} / \mathrm{ml})$ was administered by gavage to pregnant $L h \times 2$ floxed ( $L h \times 2$ conditional knock-out, $\left.L h x 2^{\text {lox/lox }}\right)$ females that had been mated with CreER;Lh $x 2^{+/-}$males. Control (CreER;Lh $x 2^{\text {lox/+ }}$ ) and conditional $\operatorname{Lh} \times 2$ mutant $\left(\mathrm{CreER} ; \operatorname{Lh} \times 2^{\text {lox/-}}\right)$ littermates were then analyzed for eye development.

Microarray. Microarray analysis was performed in duplicate essentially as previously described (de Melo et al., 2011), using retinae dissected from E13.5 control $\left(L h x 2^{\text {lox/lox }}\right)$ and mutant (Chx10-Cre; Lhx $\left.2^{\text {lox/lox }}\right)$ animals.

\section{Results}

The Lhx2 mutant displays an abnormal vesicle at the DTB

In coronal sections at E12.5, Lhx2 mutant brains display a curious vesicle-like protrusion arising at the DTB, between the caudal ganglionic eminence (CGE) and the hypothalamus, which is not seen in normal brains (Fig. 1). This vesicle expresses multiple EFTFs and other transcription factors known to be expressed in the developing eye, including Rax, Six3, Pax6, Mab2112, and Otx2
(Fig. 1A-E) (Hill et al., 1991; Acampora et al., 1995; Grindley et al., 1995; Matsuo et al., 1995; Oliver et al., 1995; Furukawa et al., 1997a; Mathers et al., 1997; Yamada et al., 2004). It also expresses Fgf17 and Wnt8b, which are normally seen limited to the optic stalk (Fig. 1 F, G) (Lako et al., 1998; Adler and Canto-Soler, 2007). Horizontal sections reveal the Wnt8b-expressing vesicle contiguous with the neuroepithelium at the junction of the telencephalon and diencephalon (Fig. 1). This is the only Raxpositive vesicle seen at all stages examined. Whole-mount in situ hybridization at E10.5 and E9.25 reveals a single Rax-expressing vesicle in control and mutant brains. At E8.25, a reduced territory of Rax expression is seen in the neural plate, consistent with earlier reports (Fig. 1) (Tetreault et al., 2009; Yun et al., 2009).

\section{Temporal analysis of LHX2 function in the developing optic vesicle}

We hypothesized that LHX2 may be required to position the optic sulcus itself, a process that is complete by E8.5 when the sulcus is apparent in control brains (Theiler, 1972). We tested the requirement of LHX2 in this process with a conditional knock-out strategy using a floxed $L h \times 2$ mouse line (Mangale et al., 2008) crossed with the ubiquitously expressing tamoxifeninducible CreER line. Tamoxifen administration at E8.25 recapit- 

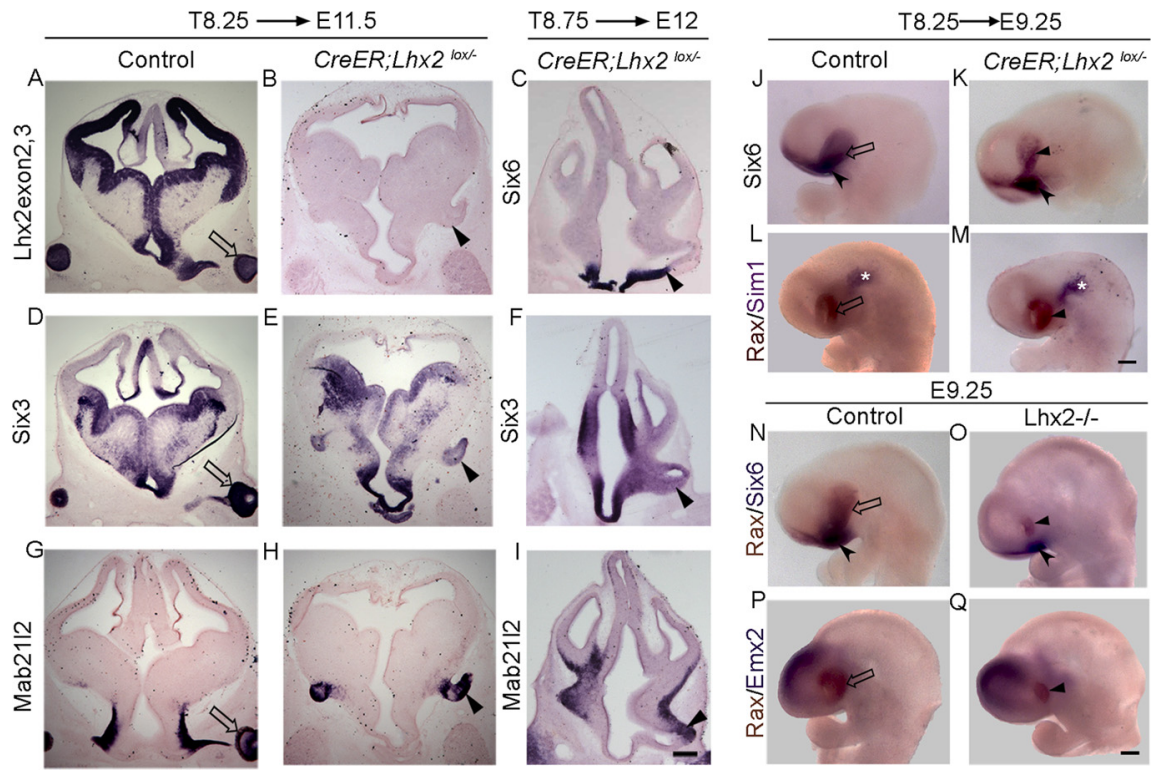

Figure 2. Altering the timing of $L h \times 2$ inactivation partially rescues the mutant phenotype. $A-I$, Conditional deletion of $L h x 2$ using a tamoxifen-inducible CreER driver. Tamoxifen administration at E8.25 (A,D,G, T8.25) does not interfere with optic development in control embryos. In floxed (CreER;L $h \times 2^{\text {lox/- }}$ ) embryos, tamoxifen administration at E8.25 produces a vesicle at the DTB $(\boldsymbol{B}, \boldsymbol{E}, \boldsymbol{H}$, arrowheads). A probe against $L h \times 2$ exon 2,3 indicates that $L h \times 2$ deletion has occurred throughout the brain $(\boldsymbol{B})$. Serial sections of the same embryo reveal the expression of optic markers Six3 $(\boldsymbol{E})$ and Mab21/2 $(\boldsymbol{H})$ in the mutant vesicle. In floxed embryos, tamoxifen administration at E8.75 (T8.75) produces a vesicle positioned intermediate between the wild-type and null mutant location $(\boldsymbol{C}, \boldsymbol{F}, \boldsymbol{I})$. Six6 is expressed in the hypothalamus and in the stalk of the mutant vesicle ( $\boldsymbol{C}$, arrowhead), and $\operatorname{Six} 3(\boldsymbol{F})$ and Mab21/2 (I) are seen in the vesicle itself, which does not progress to the optic cup stage. $\boldsymbol{J}-\mathbf{Q}$, Whole-mount preparations of E9.25 brains. $\boldsymbol{J}-\boldsymbol{M}$, Tamoxifen administration at E8.25 and examination at E9.25 reveals similar territories of expression of optic marker Six6 in the optic vesicle ( $\boldsymbol{J}$, open arrow; $\boldsymbol{K}$, arrowhead); notched arrowheads indicate Six6 expression in the hypothalamus in both control and $L h x 2$ conditional mutant brains $(\boldsymbol{J}, \boldsymbol{K})$. Similarly, a two color in situ reveals comparable expression of optic marker Rax (brown, $\boldsymbol{L}$, open arrow; $\boldsymbol{M}$, arrowhead) and anterodorsal hypothalamic marker Sim 1 (purple, asterisk) in control and conditional mutant brains. $\mathbf{N}-\mathbf{Q}$, Two color in situ hybridization of E9.25 control and $L$ hx2 standard knock-out ( $-/-)$ embryos reveals a reduced Rax-expressing vesicle (brown) in the mutants (arrowheads) compared with controls (open arrows). Six6 expression $(\boldsymbol{N}, \mathbf{0}$, purple) is seen in the hypothalamus (notched arrowhead), and Emx2 expression identifies the dorsal telencephalon $(\boldsymbol{P}, \mathbf{Q}$, purple) in both control and mutant embryos. Scale bars: $\boldsymbol{A}-\mathbf{I}, 300 \mu \mathrm{m} ; \boldsymbol{J}-\mathbf{Q}, 200 \mu \mathrm{m}$.

ulated the Lhx2 null mutant phenotype of vesicles arising at the $\mathrm{DTB}$ as seen at E11.5 (T8.25 $\rightarrow$ E11.5). A probe specific to the Lhx2 floxed exon $(2,3)$ reveals normal expression in control embryos but demonstrates that floxing appears complete across the entire forebrain in conditional mutant littermates. The mislocalized conditional mutant vesicle expresses EFTFs Six3 and Mab21l2 (Fig. 2) and appears to be very similar to the null mutant. This supports the interpretation that the sulcus is likely to be positioned normally at early stages, but its relative position becomes altered by LHX2-dependent morphogenesis occurring in the telencephalon and hypothalamus after E8.25. To clarify this further, we administered tamoxifen at E8.75, when optic development is well underway, and examined these embryos at E12 (T8.75 $\rightarrow$ E12). This produced a curious intermediate phenotype of vesicles that were neither normally positioned nor as grossly mispositioned as in the standard knock-out or in T8.25 embryos (Fig. 2). That the position of the vesicle appears partially shifted by $L h x 2$ deletion when optic development is well underway strongly supports the interpretation that its apparent mislocalization may be the result of disrupted morphogenesis of structures that surround the optic sulcus. Supporting this interpretation, the mispositioning becomes apparent only when the development of these surrounding structures has progressed sufficiently, which may explain why it was not detected in earlier studies that did not examine stages beyond E10.25 (Tetreault et al., 2009; Yun et al., 2009). Indeed, when T8.25 embryos were examined $1 \mathrm{~d}$ later, at E9.25, their expression of Six6, Rax, and hypothalamic marker Sim 1 appears very similar to controls (Fig. $2 J-M$ ). Lhx2 standard knock-out embryos examined at E9.25 display an optic vesicle that is reduced in size compared with T8.25 embryos, but the relative positions of the Rax expressing domain in the optic vesicle Six 6 in the hypothalamus and $E m \times 2$ in the telencephalon is similar to that in control embryos (Fig. 2N-Q).

Although deletion of $L h \times 2$ at E8.75 permitted partial rescue of the morphogenesis, it was striking that the vesicle still seemed to have arrested in its development compared with control embryos, in that it did not progress to the optic cup stage (Fig. 2). Therefore, we tested whether a further delay in floxing would reveal a new role for LHX2. Administering tamoxifen at E9.25 and examination at $\mathrm{E} 12(\mathrm{~T} 9.25 \rightarrow \mathrm{E} 12)$ revealed that optic development had indeed progressed further, with the formation of partial optic cups, pigmented epithelium, as well as lateappearing markers Six6 and Mitf that the standard knock-out vesicle failed to express (Fig. 3).

Lhx2 is prominently expressed in mouse retinal progenitors into the postnatal period (Blackshaw et al., 2004; Trimarchi et al., 2008; de Melo et al., 2012), although its role in controlling later stages of retinal differentiation is unknown. We examined this by using a Chx10-Cre transgenic line that expresses specifically in neuroretinal progenitors beginning at E11.5 (Rowan and Cepko, 2004). Retinae of Chx10Cre; $\operatorname{Lh} x 2^{\text {lox/lox }}$ embryos were substantially smaller but displayed markers of retinal progenitors Rorb and Rax, as well as markers of early photoreceptors Crx and Prdm1, detectable at both E13.5 and P0 (Fig. 3) (Chen et al., 1997; Furukawa et al., 1997a,b; Mathers et al., 1997; Andre et al., 1998; Chow et al., 1998; Chang et al., 2002). However, the retinae displayed gross disorganization and rosetting by E13.5, which was even more pronounced by $\mathrm{P} 0$. Together, the results reveal that LHX2 is required in an ongoing manner for the progressive morphogenesis and differentiation of the optic vesicle, and subsequently of the retina as well.

\section{Microarray analysis of $L h x 2$ conditional mutant retinae}

To comprehensively analyze changes in gene expression resulting from the selective loss of $L h \times 2$ in neuroretina, we conducted microarray analysis in E13.5 retinae taken from Chx10-Cre; Lhx $2^{\text {lox/lox }}$ mice and control Lhx $2^{\text {lox/lox }}$ littermates (Table 1). We observed that mutant retinae showed substantially reduced expression of a range of genes selectively expressed in retinal progenitors, including Chx10 and Foxn4 (Table 1) (Liu et al., 1994; Gouge et al., 2001). Other retinal progenitor-enriched genes, such as Rax, and Rorb, and early photoreceptor markers Prdm1 and Crx showed reduced expression but were readily detectable by in situ hybridization (Fig. 3; Table 1). Surprisingly, we also found a dramatic upregulation of genes selectively expressed in the thalamic eminence and anterodorsal hypothalamus, such as Lhx1, Lhx5, Tbr1, 
Sim1, and Otp in the Lhx2 conditional mutant neuroretina microarray (Table 1) (Fan et al., 1996; Acampora et al., 1999; Shimogori et al., 2010; Roy et al., 2013). We examined these markers to analyze the patterning of the mutant optic vesicle and surrounding structures, the thalamic eminence, and anterodorsal hypothalamus.

\section{LHX2 suppresses alternate fates in the optic vesicle/retina}

To study the patterning of structures surrounding the $L h \times 2$ mutant vesicle, we examined the expression of markers that identify specific regions of the hypothalamus, diencephalon and telencephalon. In a recent study, we reported the thalamic eminence to be grossly expanded and the caudal ganglionic eminence to be mispatterned and shrunken in the $L h \times 2$ standard knock-out (Fig. 4B-E) (Roy et al., 2013). The mutant vesicle is physically contiguous with the thalamic eminence (best seen in Fig. $4 E$ ). Consistent with this location, we found the mutant vesicle to express markers that are also seen in the thalamic eminence. Of these, $A P 2 \alpha$ is specific to the thalamic eminence and not normally seen in the developing optic cup or elsewhere in the forebrain (Fig. 4A). The aberrant expression of $A P 2 \alpha$ in the mutant vesicle, together with other genes normally seen in the thalamic eminence but not in the optic cup, such as $\operatorname{Lh} x 1, \operatorname{Lh} x 5, \operatorname{Lh} x 9$, and Tbr1, indicate that some regions of the mutant vesicle have acquired a thalamic eminence-like identity (Fig. 4B-E). Surprisingly, the mutant vesicle also expressed markers specific to the anterodorsal hypothalamus, such as $\operatorname{Sim} 1$ and Otp (Fig. 4F, G). Furthermore, these markers revealed a profound mispatterning of the hypothalamus, with their expression appearing in a greatly expanded and shifted domain that entered into the caudal ganglionic eminence.

Mab21l2 and Zic2, which are normally seen in most of the anterior hypothalamus, the thalamic eminence, and in the normal eye, are also expressed in the mutant vesicle. The $L h \times 2 \mathrm{mu}-$ tant anterior hypothalamus appeared mispatterned, however, in that it failed to express Mab2112 and Zic2. Furthermore, it displayed very limited expression domains of the anteroventral hypothalamic marker $\operatorname{Vax} 1$ and intrahypothalamic diagonal markers $L h x 1$ and $A r x$ compared with their expression in controls (Fig. $4 H-L$ ) (Shimogori et al., 2010). In contrast, the posteroventral hypothalamus appears to display similar patterns of $S h h$ and $N k \times 2.1$ expression in mutant and control brains (Fig. $4 M, N$ ).

In summary, the $L h x 2$ null mutant vesicle appears to display a mixed identity, displaying molecular signatures corresponding to optic, thalamic eminence, and anterodorsal hypothalamic regions. These findings are summarized in a Venn diagram (Fig. 4O). It is possible that some of these genes may actually mediate some of the patterning disruption seen in the Lhx2 mutant telencephalic-optic-hypothalamic field. To test this idea, we ex-
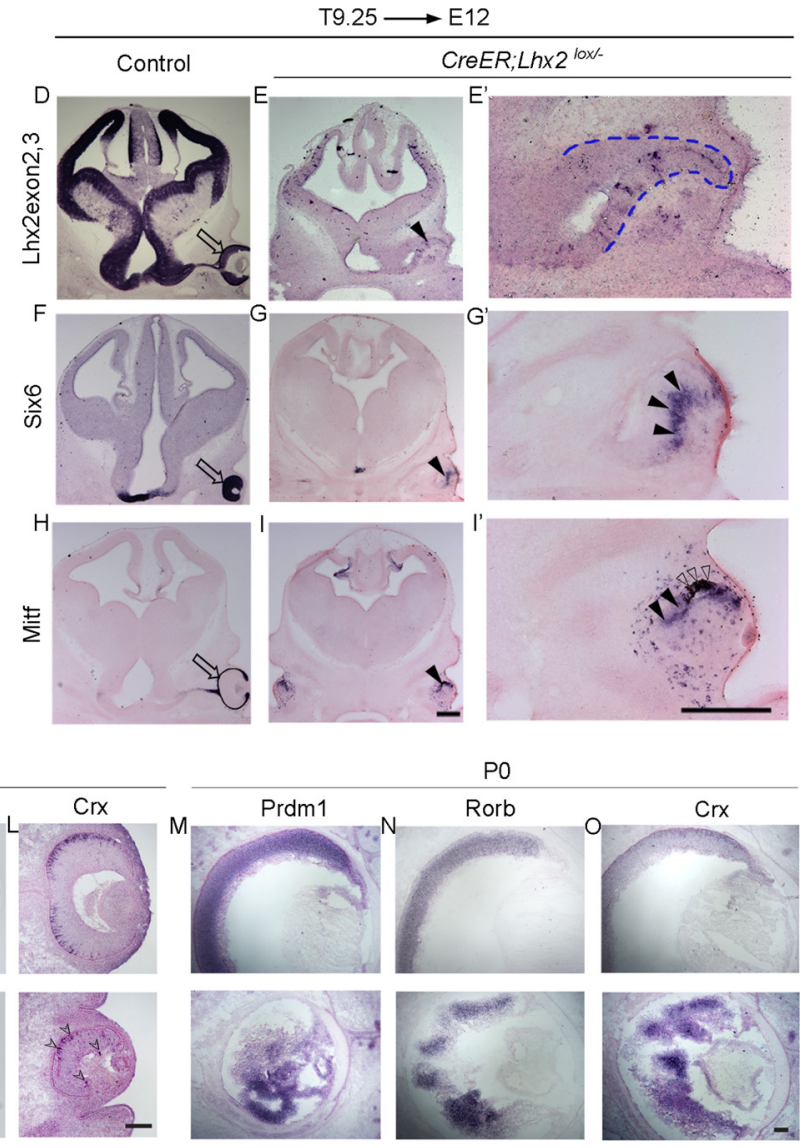

Figure 3. Late removal of $L h \times 2$ permits partial rescue of optic development. $\boldsymbol{A}-\boldsymbol{C}$, Late-arising optic transcription factors $C h \times 10$, $(\boldsymbol{D}, \boldsymbol{F}, \boldsymbol{H})$. In $L h \times 2$ floxed embryos, tamoxifen administration at $\mathrm{E9} .25$ and examination at $\mathrm{E} 12$ reveal a normally positioned vesicle mutant optic cup as well $\left(\mathbf{G}, \mathbf{G}^{\prime}, \mathbf{I}, \mathbf{I}^{\prime}\right.$, arrowheads). $\mathbf{J}-\mathbf{0}$, Retinae from control and Chx10-Cre; Lhx $2^{\text {lox/lox }}$ (conditional mutant) embryos, harvested at E13.5 $(\boldsymbol{J}-\boldsymbol{L})$ and $\mathrm{PO}(\boldsymbol{M}-\mathbf{0})$. Compared with the controls, the mutant retinae are smaller and display profound

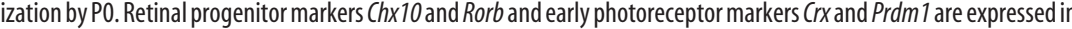
the conditional mutant neuroretina at E13.5 $(\boldsymbol{J}-\boldsymbol{L})$ and P0 $(\boldsymbol{M}-\mathbf{0}) . \boldsymbol{L}$, Open notched arrowheads show normally positioned as well as displaced immature photoreceptors in a disorganized mutant retina. Scale bars: $\boldsymbol{A}-\boldsymbol{I}^{\prime}, 300 \mu \mathrm{m} ; \boldsymbol{J}-\mathbf{0}, 100 \mu \mathrm{m}$.

amined T8.75 $\rightarrow$ E12 and T9.25 $\rightarrow$ E12 conditional Lhx2 mutants (Fig. 5). Surprisingly, in each case, robust expression of $L h \times 5$, Otp, and Sim1 was seen in the mutant optic vesicle/optic cup, demonstrating that the requirement of LHX2 for suppressing alternate tissue fates in the developing eye continues even after the optic vesicle-to-optic cup transition has occurred (Fig. 5). These results support the interpretation that LHX2 functions to suppress alternative regional fates in the optic vesicle independent of any other roles it plays in patterning the structures surrounding the optic vesicle.

\section{Distinct territories in the $L \boldsymbol{h} \mathbf{x} \mathbf{2}$ mutant vesicle/retina}

Upon close examination of the aberrant Sim 1 and Otp expression in the partial optic cups seen in adjacent sections of T9.25 $\rightarrow$ E12 brains (Fig. $5 J^{\prime}, L^{\prime}$ ), it appeared that the expression domains of these genes overlap well. We therefore examined whether the "mixed identity" observed in the Lhx2 mutant optic vesicle/optic cup displays regionalization (i.e., whether there are distinct territories corresponding optic and non-optic fates). Chx10-Cre; Lhx2 conditional mutant retinae analyzed at E13.5 displayed 
Table 1. Gene expression changes after loss of LHX2 in neuroretina ${ }^{a}$

\begin{tabular}{llll}
\hline Fold change $^{b}$ & Gene & Expression pattern at E13 & Reference \\
\hline-44.5 & Chx10 & RP & Liu et al., 1994 \\
-13.5 & Six6 & RP/AVHy & Jean et al., 1999 \\
-11.8 & Foxn4 & RP & Gouge et al., 2001 \\
-4.6 & Crx & Pr & Furukawa et al., 1997 \\
-4.5 & Prdm1 & Pr & Chang et al., 2002 \\
-4.0 & Rax & RP/AVHy & Mathers et al., 1997 \\
-3.1 & Rorb & RP & André et al., 1998 \\
-1.9 & Thrb & Pr & Ng et al., 2001 \\
-1.9 & Six3 & RP/thalamic eminence & Kawakami et al., 1996 \\
-1.2 & Pax6 & RP/thalamic eminence & Walther and Gruss, 1991 \\
3.3 & Trh & PvN & Lechan and Fekele, 2006 \\
15.9 & Lhx1 & Thalamic eminence & Abellán et al., 2010 \\
17.0 & Tbr1 & Thalamic eminence & Molnár et al., 2003 \\
18.0 & Otp & ADHy & Simeone et al., 1994 \\
18.7 & Lhx9 & Thalamic eminence & Abellán et al., 2010 \\
19.6 & Wnt7b & Thalamic eminence/ADHy & Shimogori et al., 2010 \\
25.2 & Fezf1 & Thalamic eminence/ADHy & Shimogori et al., 2010 \\
25.4 & Lhx5 & Thalamic eminence/ADHy & Abellán et al., 2010 \\
25.4 & Wnt8b & Thalamic eminence & Lako et al., 1998 \\
51.8 & Sim1 & ADHy & Michaud et al., 1998 \\
\hline
\end{tabular}

${ }^{a}$ Microarray analysis of E13.5 control ( $\left.L h \times 2^{10 x / / o x}\right)$ and Chx10cre; Lhx $2^{\text {lox/lox }}$ retinae.

${ }^{b}$ Fold changes in gene expression for mutants relative to controls are shown, together with a description of the regional expression of each gene.

ADHy, Anterodorsal hypothalamus; Pr, photoreceptor; PvN, paraventricular nucleus; RP, retinal progenitors.

clearly nonoverlapping expression of optic marker Rax compared in adjacent sections with Otp or Lhx5 expression (Fig. 6). This exclusion was maintained even in the highly dysmorphic conditional mutant retina at P0. The Lhx2 standard knock-out vesicle also displayed distinct "optic" and "non-optic" domains corresponding to Rax and Tbr1/Otp expression (Fig. 6).

\section{The Lhx2 and Pax6 mutants produce distinct optic vesicle phenotypes}

PAX6 is another crucial EFTF implicated in the transition of optic vesicle to optic cup. The Pax6 mutant is anophthalmic because optic development arrests at the optic vesicle stage (Hogan et al., 1986; Hill et al., 1991; Grindley et al., 1995). LHX2 and PAX6 have been demonstrated to interact in vitro and in retinal neurospheres to transactivate another EFTF, Six6 (Tetreault et al., 2009). We therefore examined whether the Pax6 mutant vesicles also display a mixed molecular identity. EFTFs Rax, Six3, Mab21l2, and Six6 are each expressed in the Pax6 mutant optic vesicle consistent with the extensive body of literature that has examined this mutant (Fig. 7A-D). (Hogan et al., 1986; Hill et al., 1991; Grindley et al., 1995; Bernier et al., 2001; Philips et al., 2005). Analysis with thalamic eminence markers AP2 $\alpha$, Lhx5, Lhx9, and Tbr1, showed that the Pax 6 mutant vesicle does not exhibit a mixed identity (Fig. $7 E-H$ ). Therefore, although the Lhx2 and Pax6 mutant phenotypes appear similar in that both display arrested vesicles, the phenotypes differ significantly from each other. This indicates a unique role for LHX2 in the ongoing maintenance of optic identity.

\section{Discussion}

\section{Mixed identity and apparent mislocalization of the $L h x 2$} mutant optic vesicle

In the literature, right from the first description of the anophthalmic Lhx2 mutant phenotype (Porter et al., 1997), studies have focused on what we have found to be an apparently mislocalized vesicle of mixed identity. This raises the question of why these features were not noticed earlier. One possibility is that the optic sulcus may indeed be positioned normally, but the patterning of surrounding structures and their morphogenesis may be dependent on LHX2; this produces an apparent displacement of the optic sulcus in the Lhx2 mutant. Consistent with this possibility, we find that the mislocalization is obvious only by E11.5 and is not noticeable earlier. Furthermore, we recently reported a profound mispatterning of some structures adjacent to the vesicle, the thalamic eminence and CGE in the Lhx2 mutant (Roy et al., 2013). We found the thalamic eminence to be enormously expanded in the absence of LHX2, and the CGE to be shrunken, no longer expressing appropriate markers (Roy et al., 2013), but indeed expressing genes normally seen in the anterodorsal hypothalamus Sim1 and Otp (the current study). Finally, the fact that the vesicle appears mislocalized when $L h \times 2$ is deleted from E8.25, when the optic sulcus has already begun to form, further suggests that the apparent mispositioning of the mutant vesicle may be the result of disrupted morphogenesis of the surrounding structures. Despite the severe mispatterning of these structures, we find other major forebrain regions, including the lateral and medial ganglionic eminences in the ventral telencephalon, thalamus, prethalamus, zona limitans intrathalamica, and ventral hypothalamus to be normally patterned (Bulchand et al., 2001; Lakhina et al., 2007; Roy et al., 2013) (Fig. 4), indicating a region-specific role for LHX2 rather than a general role in forebrain morphogenesis.

Nevertheless, LHX2 plays a crucial role in the specification of optic identity in the vesicle itself. Optic markers are seen only in restricted portions of the null/conditionally mutant vesicle or retina. Other regions of the mutant vesicle/retina upregulate markers that are normally expressed in the thalamic eminence and anterodorsal hypothalamus. This indicates that LHX2 function is required to continuously suppress these alternate fates. A significant contrast is seen in the Pax6 mutant, which also displays an arrested vesicle, but is normally positioned and does not display aberrant marker expression. This underscores a unique role for LHX2 in the maintenance of optic identity by suppressing alternate fates.

\section{Ongoing role of LHX2 in optic development}

We demonstrate that the degree of progress in optic development is critically dependent on the stage at which $\operatorname{Lh} \times 2$ was lost (schematized in Fig. 8). If LHX2 function is retained up to E8.75, the mispositioning of the mutant vesicles is partially rescued, but they do not progress past the vesicle stage or express lateappearing optic markers. However, if LHX2 function is retained up to E9.25, there is progression to partial optic cups with retinal pigment formation as well as expression of late-appearing optic markers, although these embryos fail to develop properly organized retinae. Loss of $L h \times 2$ from E1 1.5 onwards, in the developing neuroretina, likewise results in a dysmorphic structure that nonetheless progresses to expressing early photoreceptor markers. Nevertheless, $L h \times 2$ mutant vesicles/partial optic cups also express genes characteristic of both retina and thalamic eminence/anterodorsal hypothalamus. Together, these findings imply that LHX2 continues to act to prevent transdifferentiation of optic structures long after the eye field and adjacent domains have parted ways.

Collectively, our results offer a unique insight into the mechanisms controlling cell fate as something that must be continuously maintained by suppressing alternative identities. This insight may well apply more broadly to other systems. 
Patterning and compartmentalization of the embryonic forebrain

Previous studies have demonstrated that LHX2 is a "cortical selector," in the absence of which alternative non-cortical tissue fates expand at the expense of the cortex. The cortex is normally flanked on its medial side by the hem, on its lateral side by the antihem, and rostrally by the septum. In the $L h \times 2$ standard knock-out, the medial cortical primordium instead takes on the fate of the hem, and the lateral cortical primordium takes on the fate of the antihem, and the rostral cortical primordium takes on the fate of the septum (Bulchand et al., 2001; Mangale et al., 2008; Roy et al., 2013). LHX2 thus plays a fundamental role in suppressing these alternate, noncortical identities so that the cortical primordium may exist.

In this study, we identify what appears to be a beautiful parallel in the optic system: a role for LHX2 in maintaining optic identity, in the absence of which markers corresponding to alternative non-optic fates are seen in the optic vesicle/neuroretina. This interpretation may also provide insight into how the embryonic forebrain is compartmentalized. According to widely accepted current models of forebrain patterning, the eye field has been proposed to mark the anterior pole of the developing neuraxis (Puelles and Rubenstein, 2003), with the thalamic eminence and anterodorsal hypothalamus arising from separate and distinct prosomeric domains, each separated from the eye field by the anteroventral hypothalamus. However, the presence of markers corresponding to these two regional identities within the $L h \times 2$ mutant optic vesicle suggests a contiguous optichypothalamic-thalamic eminence domain, a finding not easily explicable by standard models of forebrain development. Our results also raise the speculation that there may be progenitors committed to distinct non-optic fates within the anterior neural plate, in which LHX2 function suppresses these identities so that the specification of optic identity occurs normally. Future studies will focus on these questions.

\section{References}

Abellán A, Vernier B, Rétaux S, Medina L (2010) Similarities and differences in the forebrain expression of Lhx1 and Lhx 5 between chicken and mouse: insights for understanding telencephalic development and evolution. J Comp Neurol 518:3512-3528. CrossRef Medline

Acampora D, Mazan S, Lallemand Y, Avantaggiato V, Maury M, Simeone A, Brûlet P (1995) Forebrain and midbrain regions are deleted in Otx2 ${ }^{-1-}$ mutants due to a defective anterior neuroectoderm specification during gastrulation. Development 121:3279-3290. Medline

Acampora D, Postiglione MP, Avantaggiato V, Di Bonito M, Vaccarino FM, Michaud J, Simeone A (1999) Progressive impairment of developing neuroendocrine cell lineages in the hypothalamus of mice lacking the Orthopedia gene. Genes Dev 13:2787-2800. CrossRef Medline

Adler R, Canto-Soler MV (2007) Molecular mechanisms of optic vesicle
Thalamic Eminence
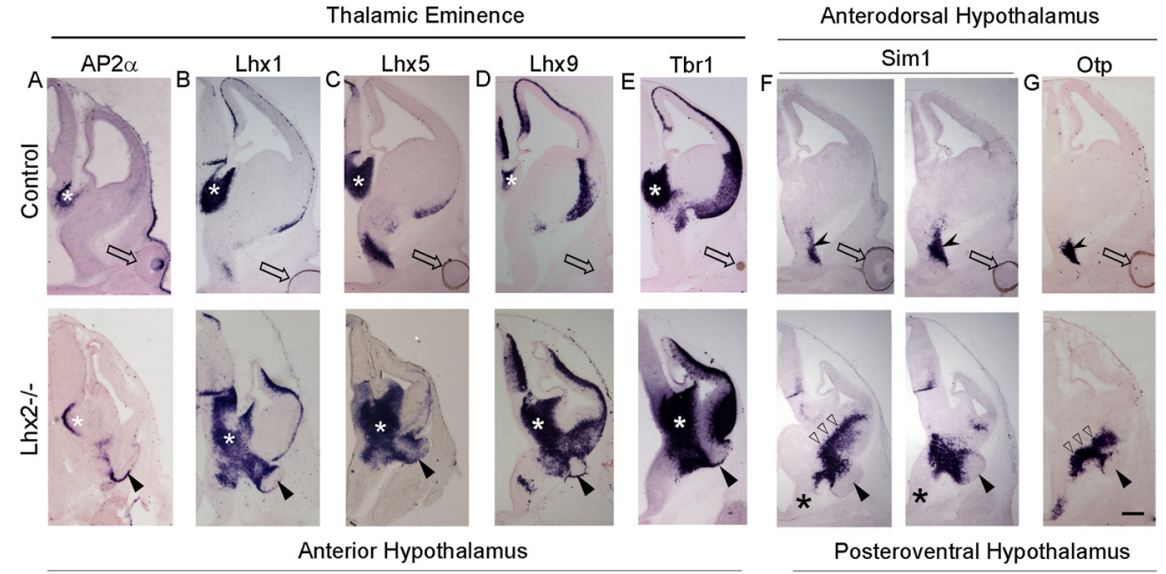

Posteroventral Hypothalamus
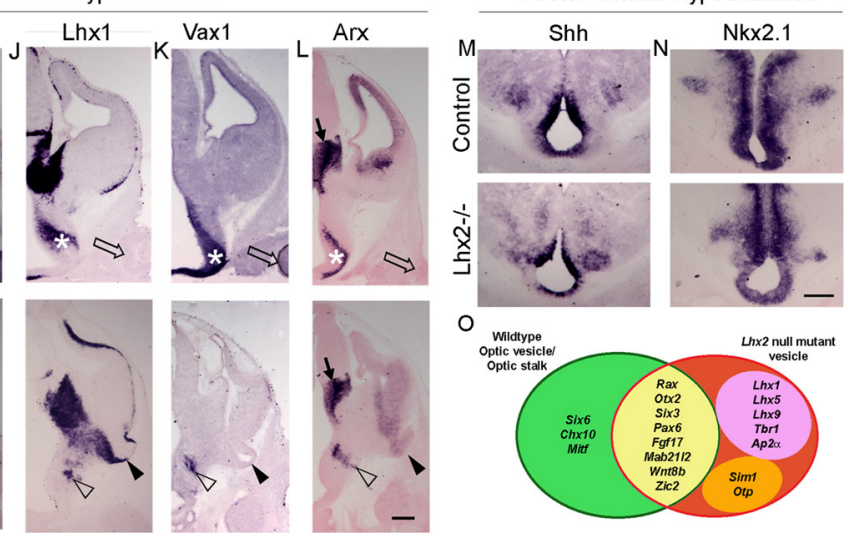

Figure 4. Loss of $L h \times 2$ disrupts patterning of the optic vesicle, the thalamic eminence, and the anterior hypothalamus. $A-E, A P 2 \alpha$, Lhx1, LhX5, LhX9, and Tbr1 are expressed in the control and Lhx2 standard knock-out thalamic eminence (white asterisk) and also in the vesicle (arrowhead), but not in the control neuroretina (open arrows; dark retinal pigment epithelium seen in some control section

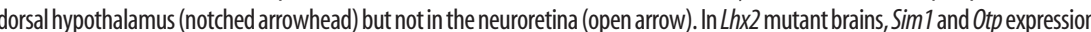
the thalamiceminence of control and $L h \times 2$ mutant brains and also appears in the $L$ hx 2 mutant vesicle $(\boldsymbol{H}-\boldsymbol{J}$, arrowheads). Mab21/2 and Zic expression is seen in the control anterior hypothalamus (white asterisk) but is not detectable in the Lhx2 mutant ( $\boldsymbol{H}, \boldsymbol{I}$, black asterisk). Lhx1, Vax1, and Arx expression is seen in the intrahypothalamic diagonal/anteroventral hypothalamus ( $\boldsymbol{J}-\boldsymbol{L}$, white asterisk), adjacent to the optic talk of control brains, but is in a very reduced and aberrantly located domain in the mutant $(\boldsymbol{J}-\boldsymbol{L}$, open arrowhead). However, some aspects

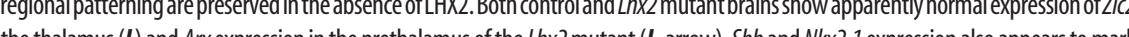
similar domains in the posteroventral hypothalamus of control and $L h \times 2$ mutant brains $(\boldsymbol{M}, \boldsymbol{N}) . \boldsymbol{0}$, The molecular patterning of the $L h \times 2$ null mutant structures are in the overlapping yellow region. Genes seen only in the mutant, but not in the control optic structures, are further divided into the pink oval, which contains genes expressed by the wild-type thalamic eminence, and orange oval, which contains genes shared by the anterodorsal hypothalamus. Arrowhead, Lhx2 mutant vesicle; open arrow, control optic cup. Scale bar, $300 \mu \mathrm{m}$.

development: complexities, ambiguities and controversies. Dev Biol 305: 1-13. CrossRef Medline

André E, Gawlas K, Becker-André M (1998) A novel isoform of the orphan nuclear receptor ROR $\beta$ is specifically expressed in pineal gland and retina. Gene 216:277-283. CrossRef Medline

Bernier G, Vukovich W, Neidhardt L, Herrmann BG, Gruss P (2001) Isolation and characterization of a downstream target of Pax6 in the mammalian retinal primordium. Development 128:3987-3994. Medline

Blackshaw S, Harpavat S, Trimarchi J, Cai L, Huang H, Kuo WP, Weber G, Lee K, Fraioli RE, Cho SH, Yung R, Asch E, Ohno-Machado L, Wong WH, Cepko CL (2004) Genomic analysis of mouse retinal development. PLoS Biol 2:E247. CrossRef Medline

Bulchand S, Grove EA, Porter FD, Tole S (2001) LIM-homeodomain gene Lhx2 regulates the formation of the cortical hem. Mech Dev 100:165-175. CrossRef Medline

Bulchand S, Subramanian L, Tole S (2003) Dynamic spatiotemporal expression of LIM genes and cofactors in the embryonic and postnatal cerebral cortex. Dev Dyn 226:460-469. CrossRef Medline 

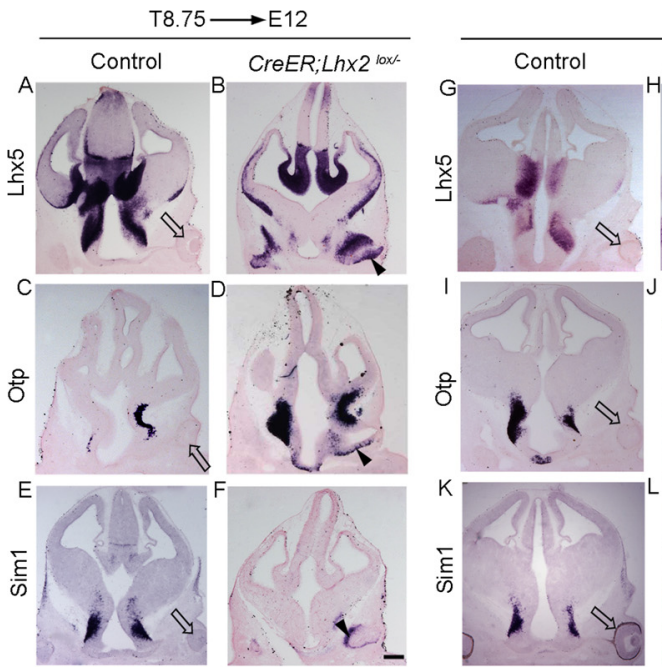

$\mathrm{T} 9.25 \longrightarrow \mathrm{E} 12$
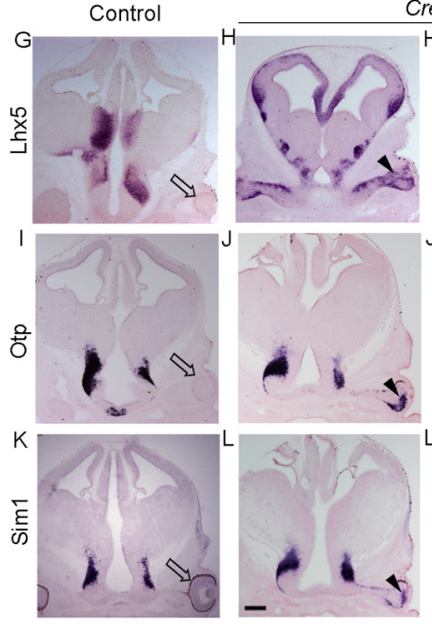

EER:Lhx2 ${ }^{\operatorname{lox} /}$

Figure 5. Ongoing role of $L H X 2$ in the suppression of alternate tissue fates. $A-L^{\prime}$, Conditional deletion of $L h \times 2$ using a tamoxifeninducible CreER driver. Tamoxifen administration at E8.75 (A,C, $\boldsymbol{E}, \mathrm{T} 8.75)$ or E9.25 (G,I, $\boldsymbol{K}, \mathrm{T}$ 9.25) does not interfere with optic development in control (CreER;LhX2 ${ }^{\text {lox/+ }}$ ) embryos. In T8.75 and T9.25 floxed embryos harvested at E12, the ectopic expression of thalamic eminence marker $L h \times 5$ and anterodorsal hypothalamic markers $0 t p$ and $\operatorname{Sim} 1$ is seen in the mutant vesicle $(\boldsymbol{B}, \boldsymbol{D}, \boldsymbol{F}$, arrowheads) and in the mutant partial optic cup ( $\boldsymbol{H}, \boldsymbol{J}, \boldsymbol{L}$, arrowheads). $\boldsymbol{H}^{\prime}, \boldsymbol{J}^{\prime}, \boldsymbol{\boldsymbol { L } ^ { \prime }}$, High magnification views of the optic cups in $\boldsymbol{H}, \boldsymbol{J}$, and $\boldsymbol{L}$, respectively. $\boldsymbol{J}, \boldsymbol{L}$, Adjacent sections reveal very similar domains of Sim 1 and Otp expression in the partial optic cup. Blue dashed lines $\left(\boldsymbol{H}^{\prime}\right)$ outline the partially formed optic cup. Open arrowheads indicate the partially formed pigmented epithelium $\left(\boldsymbol{J}^{\prime}, \mathbf{L}^{\prime}\right)$. Open arrow, control optic cup. Scale bar, $300 \mu \mathrm{m}$.
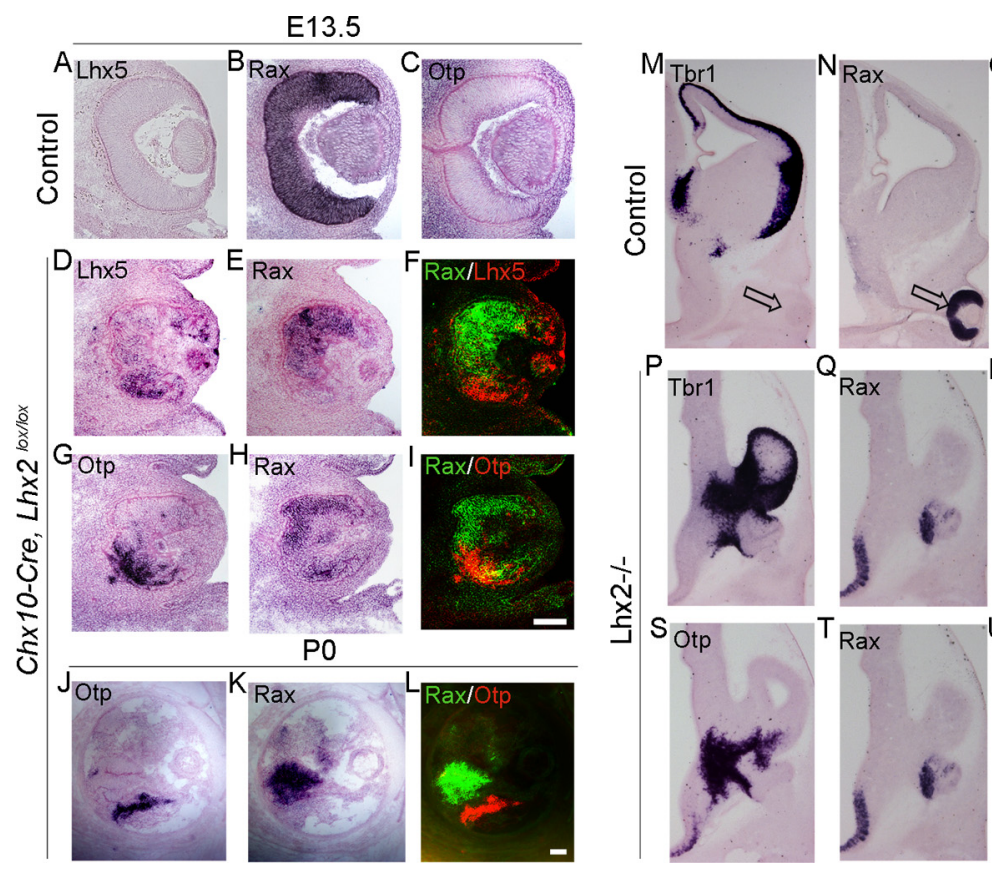

Figure 6. Distinct molecular domains within the $L h \times 2$ mutant vesicle/optic cup. $\boldsymbol{A}-\boldsymbol{L}$, Retinae from control $(\boldsymbol{A}-\boldsymbol{C})$ and $C h \times 10-C r e$; $L h \times 2^{\text {lox/lox }}(\boldsymbol{D}-\boldsymbol{L})$ embryos harvested atE13.5 (A-I) and PO (J-L).A-C, The control retina expresses Rax uniformly but does not express $L h \times 5$ or Otp. The conditional mutant retina displays patches of Rax expression $(\boldsymbol{E}, \boldsymbol{H}, \boldsymbol{K})$ that show little or no overlap with regions expressing $L h \times 5$ or Otp $(\boldsymbol{D}, \boldsymbol{G}, \boldsymbol{J}) . \boldsymbol{M}-\boldsymbol{U}$, Control and $L h \times 2$ standard knock-out embryos displaying expression of telencephalic and thalamic eminence marker Tbr1, as well as Rax and 0tp. Tbr 1 and Otp expression is absent in the Rax-positive control optic cup (M-0, open arrow). Serial sections of Lhx2 mutant embryos reveal aberrant expression of $\mathrm{Tb} 1$ and Otp in the mutant vesicle in domains that exclude the Rax expression domain. $\boldsymbol{F}, \boldsymbol{I}, \boldsymbol{L}, \boldsymbol{R}, \boldsymbol{U}$, False-color overlays of the adjacent pairs of sections. Scale bars: $\boldsymbol{A}-\boldsymbol{L}, 100 \mu \mathrm{m} ; \boldsymbol{M}-\boldsymbol{U}, 300 \mu \mathrm{m}$.

Chang DH, Cattoretti G, Calame KL (2002) The dynamic expression pattern of B lymphocyte induced maturation protein-1 (Blimp-1) during mouse embryonic development. Mech Dev 117:305-309. CrossRef Medline

Chen S, Wang QL, Nie Z, Sun H, Lennon G, Copeland NG, Gilbert DJ, Jenkins NA, Zack DJ (1997) Crx, a novel Otx-like paired-homeodomain
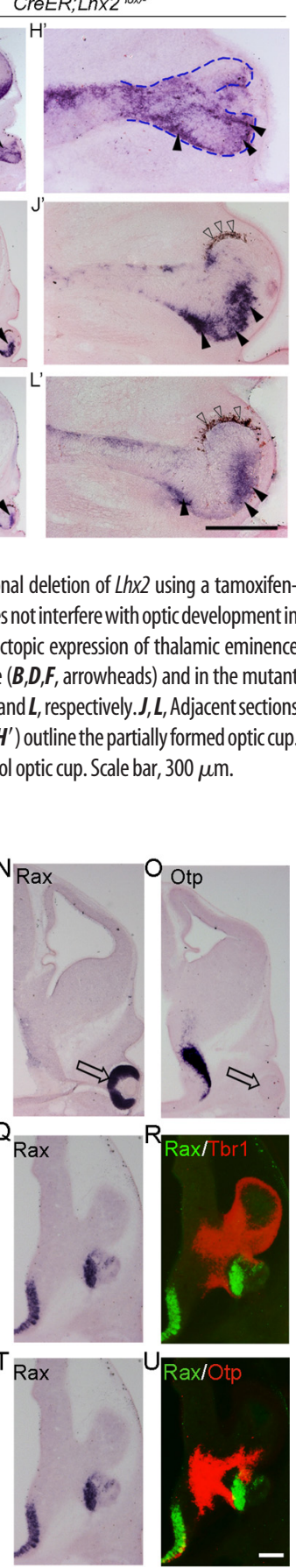

protein, binds to and transactivates photoreceptor cell-specific genes. Neuron 19:10171030. CrossRef Medline

Chow L, Levine EM, Reh TA (1998) The nuclear receptor transcription factor, retinoid-related orphan receptor $\beta$, regulates retinal progenitor proliferation. Mech Dev 77:149-164. CrossRef Medline

Chow RL, Lang RA (2001) Early eye development in vertebrates. Annu Rev Cell Dev Biol 17:255-296. CrossRef Medline

de Melo J, Peng GH, Chen S, Blackshaw S (2011) The Spalt family transcription factor Sall3 regulates the development of cone photoreceptors and retinal horizontal interneurons. Development 138:2325-2336. CrossRef Medline

de Melo J, Miki K, Rattner A, Smallwood P, Zibetti C, Hirokawa K, Monuki ES, Campochiaro PA, Blackshaw S (2012) Injury-independent induction of reactive gliosis in retina by loss of function of the LIM homeodomain transcription factor Lhx2. Proc Natl Acad Sci U S A 109: 4657-4662. CrossRef Medline

Esteve P, Bovolenta P (2006) Secreted inducers in vertebrate eye development: more functions for old morphogens. Curr Opin Neurobiol 16:13-19. CrossRef Medline

Fan CM, Kuwana E, Bulfone A, Fletcher CF, Copeland NG, Jenkins NA, Crews S, Martinez S, Puelles L, Rubenstein JL, Tessier-Lavigne M (1996) Expression patterns of two murine homologs of Drosophila single-minded suggest possible roles in embryonic patterning and in the pathogenesis of Down syndrome. Mol Cell Neurosci 7:1-16. CrossRef Medline

Fitzpatrick DR, van Heyningen V (2005) Developmental eye disorders. Curr Opin Genet Dev 15:348-353. CrossRef Medline

Furukawa T, Kozak CA, Cepko CL (1997a) rax, a novel paired-type homeobox gene, shows expression in the anterior neural fold and developing retina. Proc Natl Acad Sci U S A 94: 3088-3093. CrossRef Medline

Furukawa T, Morrow EM, Cepko CL (1997b) Crx, a novel otx-like homeobox gene, shows photoreceptor-specific expression and regulates photoreceptor differentiation. Cell 91:531-541. CrossRef Medline

Gouge A, Holt J, Hardy AP, Sowden JC, Smith HK (2001) Foxn4: a new member of the forkhead gene family is expressed in the retina. Mech Dev 107:203-206. CrossRef Medline

Graw J (2003) The genetic and molecular basis of congenital eye defects. Nat Rev Genet 4:876-888. CrossRef Medline

Grindley JC, Davidson DR, Hill RE (1995) The role of Pax-6 in eye and nasal development. Development 121:1433-1442. Medline

Hill RE, Favor J, Hogan BL, Ton CC, Saunders GF, Hanson IM, Prosser J, Jordan T, Hastie ND, van Heyningen V (1991) Mouse small eye results from mutations in a paired-like homeoboxcontaining gene. Nature 354:522-525. CrossRef Medline

Hogan BL, Horsburgh G, Cohen J, Hetherington CM, Fisher G, Lyon MF (1986) Small eyes (Sey): a homozygous lethal mutation on chromosome 2 which affects the differentiation of both lens and nasal placodes in the mouse. J Embryol Exp Morphol 97:95-110. Medline

Inoue T, Nakamura S, Osumi N (2000) Fate mapping of the mouse prosencephalic neural plate. Dev Biol 219:373-383. CrossRef Medline 

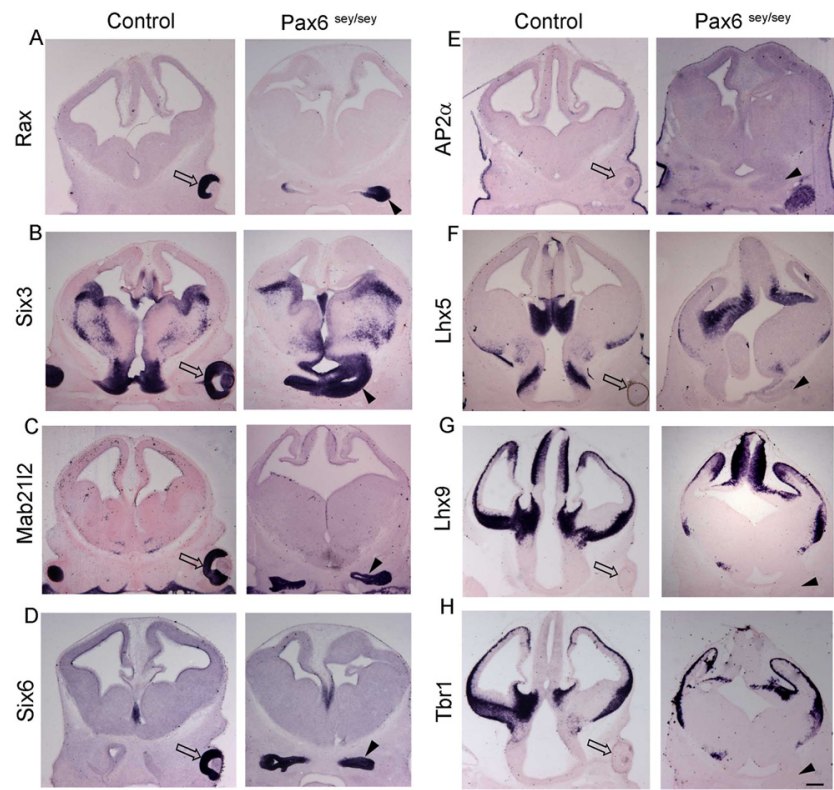

Figure 7. The Pax6 mutant optic vesicle does not display aberrant molecular identity or position. The Pax6 mutant optic vesicle, identified in coronal sections of four different E12.5 embryos, arises from a position similar to that in control brains, adjacent to the hypothalamus. Control optic cups and Pax6 mutant optic vesicles express optic transcription factors Rax, Six3, Mab2112, and Six6 (compare open arrows and arrowheads, $\boldsymbol{A}-\boldsymbol{D})$. However, neither structure expresses thalamic eminence markers $A p 2 \alpha, L h \times 5$, Lhx9, or Tbr 1 (compare open arrows and arrowheads, $\boldsymbol{E}-\boldsymbol{H}$ ). Open arrow indicates normal optic cup; arrowhead, Pax6 mutant optic vesicle. Scale bar, $300 \mu \mathrm{m}$.

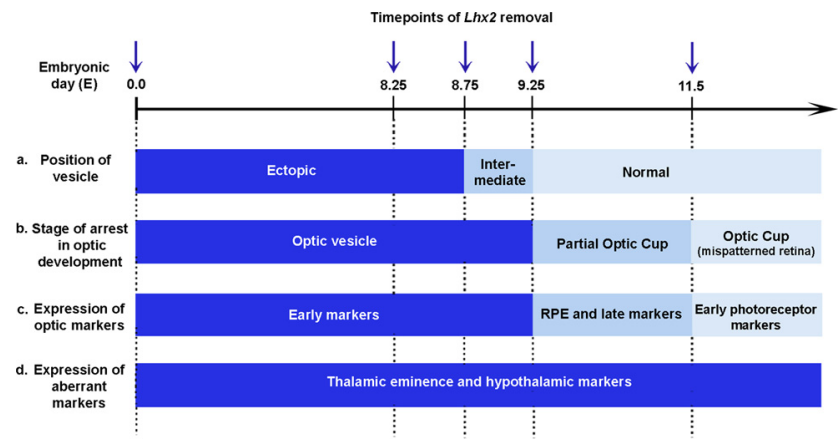

Figure 8. Multiple roles of LHX2 in optic development. A summary of the temporally dynamic roles of LHX2 in optic development. The $x$-axis represents the timing of LhX2 deletion: from E0.0 (standard knock-out), or conditionally using tamoxifen-inducible CreER from E8.25/E8.75/E9.25, or using the retina-specific Chx10-Cre, which acts from E11.5. $\boldsymbol{a}$, The position of the mutant vesicle is ectopic, intermediate, or normal depending on the timing of $L h \times 2$ deletion. $\boldsymbol{b}$, The optic vesicle arrests without forming an optic cup if $L$ hx2 is deleted before or at E8.75. c, Late optic markers, including retinal pigmented epithelium, are seen if LHX2 function is allowed to persist upto E9.25 $\boldsymbol{d}$, However, LHX2 is continuously required to suppress alternate tissue fates even after the retina has formed, and its deletion at all stages examined causes aberrant marker expression in the optic structures.

Jean D, Bernier G, Gruss P (1999) Six6 (Optx2) is a novel murine Six3related homeobox gene that demarcates the presumptive pituitary/hypothalamic axis and the ventral optic stalk. Mech Dev 84:31-40. CrossRef Medline

Kawakami K, Ohto H, Takizawa T, Saito T (1996) Identification and expression of six family genes in mouse retina. FEBS Lett 393:259263. CrossRef Medline

Lakhina V, Falnikar A, Bhatnagar L, Tole S (2007) Early thalamocortical tract guidance and topographic sorting of thalamic projections requires LIM-homeodomain gene Lhx2. Dev Biol 306:703-713. CrossRef Medline

Lako M, Lindsay S, Bullen P, Wilson DI, Robson SC, Strachan T (1998) A novel mammalian wnt gene, WNT8B, shows brain-restricted expression in early development, with sharply delimited expression boundaries in the developing forebrain. Hum Mol Genet 7:813-822. CrossRef Medline
Lechan RM, Fekete C (2006) The TRH neuron: a hypothalamic integrator of energy metabolism. Prog Brain Res 153:209-235. CrossRef Medline

Liu IS, Chen JD, Ploder L, Vidgen D, van der Kooy D, Kalnins VI, McInnes RR (1994) Developmental expression of a novel murine homeobox gene (Chx10): evidence for roles in determination of the neuroretina and inner nuclear layer. Neuron 13:377-393. CrossRef Medline

Mangale VS, Hirokawa KE, Satyaki PR, Gokulchandran N, Chikbire S, Subramanian L, Shetty AS, Martynoga B, Paul J, Mai MV, Li Y, Flanagan LA, Tole S, Monuki ES (2008) Lhx2 selector activity specifies cortical identity and suppresses hippocampal organizer fate. Science 319:304-309. CrossRef Medline

Martínez-Morales JR, Rodrigo I, Bovolenta P (2004) Eye development: a view from the retina pigmented epithelium. Bioessays 26:766-777. CrossRef Medline

Mathers PH, Grinberg A, Mahon KA, Jamrich M (1997) The Rx homeobox gene is essential for vertebrate eye development. Nature 387:603-607. CrossRef Medline

Matsuo I, Kuratani S, Kimura C, Takeda N, Aizawa S (1995) Mouse Otx2 functions in the formation and patterning of rostral head. Genes Dev 9:2646-2658. CrossRef Medline

Michaud JL, Rosenquist T, May NR, Fan CM (1998) Development of neuroendocrine lineages requires the bHLH-PAS transcription factor SIM1. Genes Dev 12:3264-3275. CrossRef Medline

Molnár Z, Higashi S, López-Bendito G (2003) Choreography of early thalamocortical development. Cereb Cortex 13:661-669. CrossRef Medline

Ng L, Hurley JB, Dierks B, Srinivas M, Saltó C, Vennström B, Reh TA, Forrest D (2001) A thyroid hormone receptor that is required for the development of green cone photoreceptors. Nat Genet 27:94-98. CrossRef Medline

Oliver G, Mailhos A, Wehr R, Copeland NG, Jenkins NA, Gruss P (1995) Six 3 , a murine homologue of the sine oculis gene, demarcates the most anterior border of the developing neural plate and is expressed during eye development. Development 121:4045-4055. Medline

Philips GT, Stair CN, Young Lee H, Wroblewski E, Berberoglu MA, Brown NL, Mastick GS (2005) Precocious retinal neurons: Pax6 controls timing of differentiation and determination of cell type. Dev Biol 279:308-321. CrossRef Medline

Porter FD, Drago J, Xu Y, Cheema SS, Wassif C, Huang SP, Lee E, Grinberg A, Massalas JS, Bodine D, Alt F, Westphal H (1997) Lhx2, a LIM homeobox gene, is required for eye, forebrain, and definitive erythrocyte development. Development 124:2935-2944. Medline

Puelles L, Rubenstein JL (2003) Forebrain gene expression domains and the evolving prosomeric model. Trends Neurosci 26:469-476. CrossRef Medline

Rowan S, Cepko CL (2004) Genetic analysis of the homeodomain transcription factor Chx10 in the retina using a novel multifunctional BAC transgenic mouse reporter. Dev Biol 271:388-402. CrossRef Medline

Roy A, Gonzalez-Gomez M, Piernai A, Meyer G, Tole S (2013) Lhx2 regulates the development of the forebrain hem system. Cereb Cortex Advance online publication. Retrieved January 10, 2013. doi:10.1093/ cercor/bhs421. CrossRef Medline

Shimogori T, Lee DA, Miranda-Angulo A, Yang Y, Wang H, Jiang L, Yoshida AC, Kataoka A, Mashiko H, Avetisyan M, Qi L, Qian J, Blackshaw S (2010) A genomic atlas of mouse hypothalamic development. Nat Neurosci 13:767-775. CrossRef Medline

Simeone A, D'Apice MR, Nigro V, Casanova J, Graziani F, Acampora D, Avantaggiato V (1994) Orthopedia, a novel homeobox-containing gene expressed in the developing CNS of both mouse and Drosophila. Neuron 13:83-101. CrossRef Medline

Tétreault N, Champagne MP, Bernier G (2009) The LIM homeobox transcription factor Lhx2 is required to specify the retina field and synergistically cooperates with Pax6 for Six6 trans-activation. Dev Biol 327:541550. CrossRef Medline

Theiler K (1972) The house mouse: development and normal stages from fertilization to 4 weeks of age. Berlin: Springer.

Trimarchi JM, Stadler MB, Cepko CL (2008) Individual retinal progenitor cells display extensive heterogeneity of gene expression. PLoS One 3:e1588. CrossRef Medline

Walther C, Gruss P (1991) Pax-6, a murine paired box gene, is expressed in the developing CNS. Development 113:1435-1449. Medline 
Wilson SW, Houart C (2004) Early steps in the development of the forebrain. Dev Cell 6:167-181. CrossRef Medline

Yamada R, Mizutani-Koseki Y, Koseki H, Takahashi N (2004) Requirement for Mab2112 during development of murine retina and ventral body wall. Dev Biol 274:295-307. CrossRef Medline

Yun S, Saijoh Y, Hirokawa KE, Kopinke D, Murtaugh LC, Monuki ES, Levine
EM (2009) Lhx2 links the intrinsic and extrinsic factors that control optic cup formation. Development 136:3895-3906. CrossRef Medline

Zuber ME, Gestri G, Viczian AS, Barsacchi G, Harris WA (2003) Specification of the vertebrate eye by a network of eye field transcription factors. Development 130:5155-5167. CrossRef Medline 